\title{
Weight gain during the first year of life in relation to maternal smoking and breast feeding in Norway
}

Per Nafstad, Jouni J K Jaakkola, Jørgen A Hagen, Babill Stray Pedersen, Erik Qvigstad, Grete Botten, Johny Kongerud not, however, consider nutrition during the first year of life. Feeding practices during the first year of life may be important in explaining catch up growth. In at least two previous studies children who were not breast fed had a higher rate of growth than those who were. ${ }^{89}$ Furthermore, maternal smoking was inversely associated with the length of breast feeding, ${ }^{10}$ suggesting that breast feeding is a potential confounding factor in the study of smoking and weight gain.

A cohort of newborns was established in Oslo, Norway during 1992 and 1993. The data collected included information on birth weight, weight at 1 year, maternal smoking, and breast feeding practices during the first year of life. The objective of the present study was to assess the weight gain during the first year of life in relation to maternal smoking during pregnancy and breast feeding. $(6776 \mathrm{~g})$ in children of non-smoking and light and heavy smoking mothers respectively. Cox regression analysis showed that children of heavy smokers were $\mathbf{2 . 0}$ (95\% confidence interval, $1.7,2.3)$ times and children of light smokers $1.3(1.2,1.5)$ times more likely to have stopped breast feeding during their first year of life compared with children whose mothers were non-smokers. Linear regression analysis, adjusting for confounders, showed that weight gain was slower in breast fed children than in those who were not breast fed $(-38 \mathrm{~g}(-50,-27)$ per month of breast feeding). Compared with children of nonsmokers, the adjusted weight gain was $147 \mathrm{~g}(40,255)$ per year greater in children of light smokers and $184 \mathrm{~g}(44,324)$ per year in children of heavy smokers.

Conclusion-Children catch up any losses in birth weight due to maternal smoking, but some of the catch up effect is caused by a shorter duration of breast feeding in children of smoking mothers.

\section{( $\mathcal{F}$ Epidemiol Community Health 1997;51:261-265)}

Smoking during pregnancy has adverse effects on fetal growth and results in low birth weight. ${ }^{1-3}$ It has been suggested that deficits in child development due to maternal smoking in pregnancy may persist during childhood, and even into adulthood. ${ }^{4-6}$ Conter et al reported recently that children exposed to maternal smoking during pregnancy had caught up in body weight by the age of 6 months. ${ }^{7}$ They did

\section{Methods}

RECRUITMENT AND DATA COLLECTION

The source population included children born during a period of 15 months in the city of Oslo. The eligibility criteria were: permanent address within the city of Oslo, no plans for moving from Oslo within the near future, birth weight greater than $2000 \mathrm{~g}$, at least one family member able to speak and write Norwegian, at least one biological parent living together with the child, and no known drug abuse in the family. As this was a part of a study of the relation between environmental exposures and the development of obstructive respiratory symptoms in childhood, children born with serious illnesses which might impair respiration and children who had received assisted ventilation or oxygen therapy after 6 hours of life were excluded. Children with low birth weight were excluded due to an expected high risk of being born with respiratory diseases and a high awareness among their parents and doctors of symptoms and illnesses during childhood.

Recruitment into the study was conducted by midwives at the two main maternity clinics in Oslo. A total of 6400 children were born at the hospitals during the recruitment period. Language problem (in immigrants) was the main reason for exclusion $(n=1045)$, together with address outside Oslo $(n=180)$ and low birth weight $(n=160)$.

A maximum of 4973 children were found eligible for the cohort. Families fulfilling the inclusion criteria were informed about the main 
objectives of the study during their stay on the maternity wards and invited to participate. Of the eligible families, 3754 (76\%) accepted the invitation. Participants signed a consent form and filled in unaided a health and exposure questionnaire. Birth weight and gestational age were recorded from hospital files. Umbilical cord blood samples were collected from $79 \%$ of the participants. When the child was 6 and 12 months old, the participating families received postal questionnaires on health and environmental exposures during the first year of life.

The study was approved by the Norwegian Data Inspectorate and the Regional Ethical Committee for Medical Research.

\section{STUDY POPULATION}

Of the 3754 children entered into the cohort, $3020(81 \%)$ were included in the present analysis. Twins $(n=88)$ were excluded from the analysis, together with 296 children from families who did not reply to the 12 months questionnaire and 350 children for whom information on birth weight, body weight at age 1 year, maternal smoking, or duration of breast feeding was missing.

\section{OUTCOME MEASURES}

The main outcome was the average weight gain (in $\mathrm{g}$ per year) during the first year of life. Weight $(\mathrm{g})$ and length $(\mathrm{cm})$ at the age of 1 year were measured by nurses at the routine health controls conducted at local health centres. Results from the most recent measurements were reported in the 12 month questionnaire together with the date of the measurements. Based on these data and the date of birth, the children's exact age at the measurements was calculated. Weight and length at the age of 1 year were then calculated by applying correction factors based on standard Norwegian centile diagrams ${ }^{11}$ and the children's exact age at the measurements. Weight gain during the first year of life was calculated as the weight at age 1 year minus the birth weight. According to the standard Norwegian centile diagrams, the 50th centile birth weight for boys was $3600 \mathrm{~g}$ and that for girls was $3450 \mathrm{~g}$, and the weights for age 1 year were $10400 \mathrm{~g}$ and $9700 \mathrm{~g}$ respectively. Body mass index was calculated as weight $(\mathrm{kg}) /\left(\right.$ length $\left(\mathrm{m}^{2}\right){ }^{12}$

\section{KEY POINTS}

- Any reduction in birth weight related to maternal smoking during pregnancy seems to be overcome by 1 year of age.

- Part of the increased weight gain in infants of mothers who smoke seems to be due to a shorter duration of breast feeding in these children.

- Weight gain related to maternal smoking and a shorter period of breast feeding may not represent a recovery from the adverse effects of smoking during pregnancy.
MATERNAL SMOKING AND BREAST FEEDING

Maternal smoking during pregnancy was the main determinant of interest and was assessed by self administered questionnaire about smoking at the end of pregnancy. Using the same classification as Conter et $a l^{7}$ mothers were categorised as non-smokers, light smokers $(<10$ cigarettes per day), and heavy smokers ( $\geq 10$ cigarettes per day). Occasional smokers, those who reported smoking less frequently than each day, were categorised as light smokers. Information on smoking habits among other persons living in the child's home was also collected. Biomarkers of tobacco smoke exposure were measured in umbilical cord serum taken at birth for 202 randomly selected mothers. ${ }^{13}$ An excellent agreement was shown between high and low levels of biomarkers and daily ( $88 \%$ high cotinine levels) and non-smoking mothers ( $96 \%$ low cotinine levels) indicating that the mothers reported their smoking habits correctly. Breast feeding is presented as the duration of breast feeding in months.

\section{COVARIATES}

Information on gender, first born child, maternal age ( $<25$ years, $25-30$ years, $>30$ years), maternal education $(<12$ years, $13-15$ years, $>15$ years), single parenthood, and family income per year $(<200000 \mathrm{Nkr}, 200$ $500000 \mathrm{Nkr}$, >500000 Nkr) were collected from the birth questionnaire. Data on exposure to environmental tobacco smoke (ETS) (if the child lived together with a smoker other than the mother at the age of 6 months) and the introduction of solid food before the age of 6 months were from the 6 month questionnaire.

\section{STATISTICAL METHODS}

The association between the duration of breast feeding and maternal smoking rate was assessed

Table 1 Characteristics of children and mothers in the study population and of those lost to follow up or excluded from the analysis. Oslo birth cohort, Norway 1992-93*†

\begin{tabular}{lcc}
\hline & $\begin{array}{l}1 \text { year } \\
\text { cohort } \\
(n=3020) \%\end{array}$ & $\begin{array}{l}\text { Lost to follow } \\
\text { up or excluded } \\
(n=646) \%\end{array}$ \\
\hline Gender (male) & 52 & 52 \\
Birth weight (g): & 2 & 2 \\
$<2500$ & 42 & 44 \\
$2500-3499$ & 57 & 54 \\
+3500 & 52 & 48 \\
Firstborn child & & \\
Maternal age (y): & 11 & 17 \\
$<25$ & 36 & 38 \\
$25-30$ & 53 & 46 \\
$>30$ & 6 & 14 \\
Maternal education (y): & 39 & 44 \\
$<12$ & 55 & 42 \\
$\quad 12-15$ & 76 & 71 \\
$>15$ & 9 & 9 \\
Maternal smoking at the end of pregnancy: & \\
$\quad$ No & 14 & 20 \\
Occasional & 15 & 27 \\
Daily & 67 & 57 \\
Family income per year (Nkr): & & 16 \\
$<200000$ & 19 & 3 \\
$\quad 200-500000$ & 4 &
\end{tabular}

* 88 twins are excluded from the total cohort $(n=3754)$. tData were missing for between for 0 to 278 subjects for each + Data were missing for between for 0 to 278 subjects for each characteristic (birth weight $=20$, maternal age $=1$, maternal
education $=38$, maternal smoking at the end of pregnancy $=7$, education $=38$, maternal smoking at the end
family income $=78$, gestational age $=278$ ). 
Table 2 Family characteristics in relation to maternal smoking habits at the end of pregnancy for 3020 children in the Oslo birth cohort, Norway 1992-93†

\begin{tabular}{|c|c|c|c|c|}
\hline & \multicolumn{3}{|c|}{ Maternal smoking $\ddagger$} & \multirow[b]{2}{*}{$p$ value } \\
\hline & $\begin{array}{l}\text { Non-smoker } \\
(n=2308) \\
(\%)\end{array}$ & $\begin{array}{l}\text { Light smoker } \\
(n=451) \\
(\%)\end{array}$ & $\begin{array}{l}\text { Heavy smoker } \\
(n=261) \\
(\%)\end{array}$ & \\
\hline \multirow{2}{*}{ Gender (male) } & 53 & 46 & 56 & * \\
\hline & 53 & 52 & 49 & \\
\hline \multicolumn{4}{|l|}{ Maternal age $(y)$ : } & * \\
\hline$<25$ & 10 & 14 & 16 & \\
\hline $25-30$ & 36 & 35 & 36 & \\
\hline$>30$ & 54 & 51 & 48 & \\
\hline \multicolumn{4}{|l|}{ Maternal education (y): } & ** \\
\hline$<12$ & 4 & 8 & 19 & \\
\hline $12-15$ & 35 & 48 & 57 & \\
\hline$>15$ & 61 & 44 & 24 & \\
\hline Single parenthood at birth & 4 & 9 & 14 & ** \\
\hline \multicolumn{4}{|l|}{ Family income per year $(\mathrm{Nkr})$ : } & ** \\
\hline$<200000$ & 13 & 18 & 26 & \\
\hline $200-500000$ & 66 & 68 & 65 & \\
\hline$>500000$ & 20 & 14 & 10 & \\
\hline Breastfeeding after 6 months (yes) & 75 & 59 & 41 & ** \\
\hline Exposed to enviromental tobacco smoke & 28 & 63 & 73 & ** \\
\hline Introduction to solid food before age & 83 & 91 & 93 & $* *$ \\
\hline
\end{tabular}

† Data were missing for between for 0 to 86 subjects for each characteristic (maternal education = 23 , single parenthood $=6$, family income $=44$, exposed to $E T S=76$, introduction of solid food $=$ 86).

$¥$ Light smoker $=$ less than 10 cigarettes per day, Heavy smoker $=10$ or more cigarettes per day. Children living together with a smoker other then the mother at the age of 6 months.

$\mathrm{p}<0.05,{ }^{* *} \mathrm{p}<0.01 \chi^{2}$.

using Spearman's correlation coefficient, a survival function plot (actuarial), and Cox regression analysis. The Cox regression model met the requirements of proportional hazards. Children who were not breast fed at all $(\mathrm{n}=$ 29) were excluded from the model. The role of maternal smoking during pregnancy and the duration of breast feeding as determinants of weight gain during the first year of life were assessed in multiple linear regression analysis adjusting for confounders. Birth weight and the length of breast feeding were treated as continuous variables while the rest were categorised as described. The analysis was performed using SPSS for Windows, version 6.0. ${ }^{14}$

\section{Results}

Table 1 shows characteristics of the families and children included in the analysis and those lost to follow up or excluded. Families lost to follow up or excluded from the present analysis had lower income and the mothers were younger and less educated and tended to smoke more than those included in the analysis.

The duration of breast feeding and several of the covariates (family income, maternal age and income) were related to maternal smoking (table 2).

The mean birth weights of babies born to mothers who were non-smokers, light smokers, and heavy smokers were $3616 \mathrm{~g}, 3526 \mathrm{~g}$, and $3382 \mathrm{~g}$ respectively (table 3 ). The crude differences between smokers and non-smokers were statistically significant. The mean weight gain during the first year was higher both in the children of heavy smokers (6776 $\mathrm{g}$ per year), and light smokers (6615 g per year) compared with children of non-smokers ( $6440 \mathrm{~g}$ per year). Consequently, the mean body weight at the age of 1 year was similar in the children of smoking and non-smoking mothers. The same was also the case for the body mass index at 1 year of age. Analysis performed with uncorrected 1 year body weights or only with children with 1 year body weights measured within two weeks of the child's birthday gave similar contrasts between the groups. Differences in weight gain in relation to maternal smoking were shown in both boys and girls.

Weight gain during the first year was $6719 \mathrm{~g}$ (95\% CI, 6644, 6793) in children breast fed for $0-6$ months and $6427 \mathrm{~g}(6383,6471)$ in children breast fed for more than 6 months. For each month of breast feeding, there was a decrease in weight gain of on average $43 \mathrm{~g}$ (32, $54)$ per year; it was $33 \mathrm{~g}(18,47)$ per year in boys and $49 \mathrm{~g}(34,63)$ per year in girls.

Only $29(1 \%)$ children were not breast fed at all and $2112(70 \%)$ children were breast fed for more than six months. Maternal smoking was significantly associated with most of the covariates in table 2 . The Spearman correlation between maternal smoking and length of breast feeding (months) was $-0.23, \mathrm{p}<0.001$. Chil-

Table 3 Means (95\% confidence intervals (CI)) for birth weight, 1 year body weight, weight gain during the first year, and body mass index (BMI) at 1 year in relation to gender and maternal smoking for 3020 children in the Oslo birth cohort 1992-93t

\begin{tabular}{|c|c|c|c|c|c|c|c|c|c|}
\hline \multirow{2}{*}{$\begin{array}{l}\text { Variable/maternal } \\
\text { smoking status }\end{array}$} & \multicolumn{3}{|l|}{ Boys } & \multicolumn{3}{|l|}{ Girls } & \multicolumn{3}{|l|}{ Total } \\
\hline & No & Mean & $(95 \% C I)$ & No & Mean & $(95 \% C I)$ & No & Mean & $(95 \% C I)$ \\
\hline $\begin{array}{l}\text { Birth weight }(g) \text { : } \\
\text { Non-smoker } \\
\text { Light smoker }(<10 \mathrm{cig} / \mathrm{d}) \\
\text { Heavy smoker }(10+\mathrm{cig} / \mathrm{d}) \\
\text { Total }\end{array}$ & $\begin{array}{r}1214 \\
208 \\
145 \\
1567\end{array}$ & $\begin{array}{l}3688 \\
3573^{* *} \\
3412^{* * *} \\
3648\end{array}$ & $\begin{array}{l}(3660,3717) \\
(3502,3644) \\
(3329,3494) \\
(3622,3678)\end{array}$ & $\begin{array}{r}1094 \\
243 \\
116 \\
1453\end{array}$ & $\begin{array}{l}3536 \\
3485 \\
3345^{* * *} \\
3512\end{array}$ & $\begin{array}{l}(3507,3565) \\
(3430,3542) \\
(3265,3424) \\
(3487,3538)\end{array}$ & $\begin{array}{r}2308 \\
451 \\
261 \\
3020\end{array}$ & $\begin{array}{l}3616 \\
3526^{* * *} \\
3382^{* * *} \\
3582\end{array}$ & $\begin{array}{l}(3596,3636) \\
(3481,3571) \\
(3324,3440) \\
(3565,3600)\end{array}$ \\
\hline $\begin{array}{l}1 \text { y body weight }(g): \\
\text { Non-smoker } \\
\text { Light smoker }(<10 \mathrm{cig} / \mathrm{d}) \\
\text { Heavy smoker }(10+\mathrm{cig} / \mathrm{d}) \\
\text { Total }\end{array}$ & $\begin{array}{r}1214 \\
208 \\
145 \\
1567\end{array}$ & $\begin{array}{l}10417 \\
10523 \\
10369 \\
10427\end{array}$ & $\begin{array}{l}(10354,10480) \\
(10371,10675) \\
(10177,10561) \\
(10371,10482)\end{array}$ & $\begin{array}{r}1094 \\
243 \\
116 \\
1453\end{array}$ & $\begin{array}{l}9656 \\
9814^{*} \\
9893^{*} \\
9701\end{array}$ & $\begin{array}{l}(9595,9717) \\
(9669,9959) \\
(9705,10082) \\
(9647,9755)\end{array}$ & $\begin{array}{r}2308 \\
451 \\
261 \\
3020\end{array}$ & $\begin{array}{l}10056 \\
10141 \\
10158 \\
10078\end{array}$ & 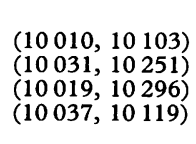 \\
\hline $\begin{array}{l}\text { Weight gain during } 1 \text { st } y \text { of life }(g / y) \text { : } \\
\text { Non-smoker } \\
\text { Light smoker }(<10 \mathrm{cig} / \mathrm{d}) \\
\text { Heavy smoker }(10+\mathrm{cig} / \mathrm{d}) \\
\text { Total }\end{array}$ & $\begin{array}{r}1214 \\
208 \\
145 \\
1567\end{array}$ & $\begin{array}{l}6729 \\
6950^{* *} \\
6957^{*} \\
6779\end{array}$ & $\begin{array}{l}(6670,6787) \\
(6807,7094) \\
(6780,7134) \\
(6727,6831)\end{array}$ & $\begin{array}{r}1094 \\
243 \\
116 \\
1453\end{array}$ & $\begin{array}{l}6120 \\
6329^{* *} \\
6549^{* * *} \\
6189\end{array}$ & $\begin{array}{l}(6063,6177) \\
(6197,6460) \\
(6368,6729) \\
(6138,6240)\end{array}$ & $\begin{array}{r}2308 \\
451 \\
261 \\
3020\end{array}$ & $\begin{array}{l}6440 \\
6615^{* * *} \\
6776^{* * *} \\
6495\end{array}$ & $\begin{array}{l}(6397,6483) \\
(6514,6717) \\
(6647,6905) \\
(6457,6533)\end{array}$ \\
\hline $\begin{array}{l}\text { BMI at } 1 \text { y: } \\
\text { Non-smoker } \\
\text { Light smoker }(<10 \mathrm{cig} / \mathrm{d}) \\
\text { Heavy smoker }(10+\mathrm{cig} / \mathrm{d}) \\
\text { Total }\end{array}$ & $\begin{array}{r}1210 \\
208 \\
144 \\
1562\end{array}$ & $\begin{array}{l}17.5 \\
17.6 \\
17.6 \\
17.5\end{array}$ & $\begin{array}{l}(17.3,17.7) \\
(17.4,17.8) \\
(17.4,17.8) \\
(17.5,17.5)\end{array}$ & $\begin{array}{r}1082 \\
241 \\
115 \\
1438\end{array}$ & $\begin{array}{l}17.1 \\
17.2 \\
17.4 \\
17.2\end{array}$ & $\begin{array}{l}(16.9,17.3) \\
(17.0,17.4) \\
(17.2,17.6) \\
(17.0,17.4)\end{array}$ & $\begin{array}{r}2292 \\
4490 \\
269 \\
3000\end{array}$ & $\begin{array}{l}17.3 \\
17.4 \\
17.5 \\
17.3\end{array}$ & $\begin{array}{l}(17.3,17.3) \\
(17.2,17.6) \\
(17.3,17.7) \\
(17.3,17.3)\end{array}$ \\
\hline
\end{tabular}

$\dagger 20$ children excluded in the analysis of body mass index because of missing information on length.

Student's $t$ test between different catergories of maternal smoking habits (non-smokers are the reference catergory).

${ }^{*}=0.05=>p>0.01,{ }^{* *}=0.01=>p>0.001,{ }^{* *}=0.001=>p$ (no correction for multiple comparison has been conducted). 


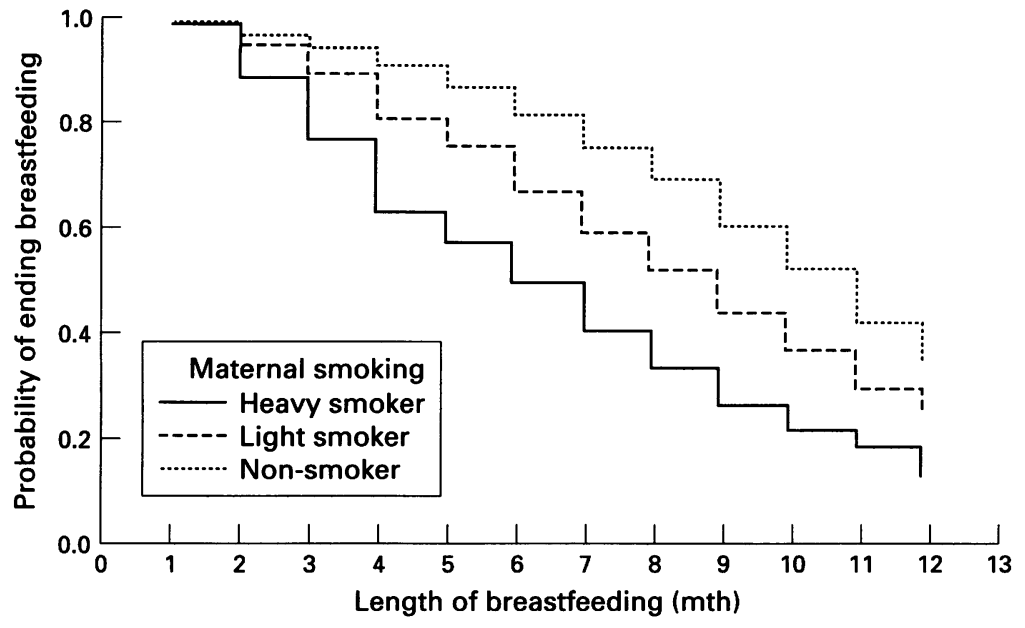

Figure 1 The duration of breast feeding (months) in 3020 children in the Oslo birth cohort in relation to maternal smoking habits in late pregnancy (actuarial).

Table 4 Weight gain during the first year of life $(g / y)$ in relation to maternal smoking and duration of breast feeding (mth) in 3020 children of the Oslo birth cohort 1992-93 (linear regression)

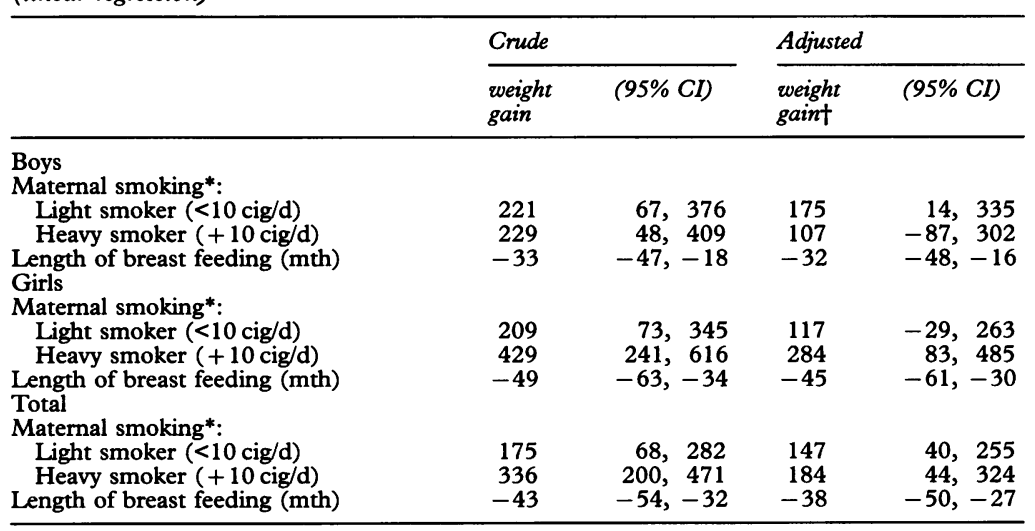

* Non-smoking mothers are the reference catergory.

† Adjusted for birth weight, time for introduction of solid food, passive smoking (other person than the mother smoking in the child's home) and first born child. Also adjusted for gender in the total (boys and girls together).

Information on maternal age, maternal education and family income were tried out but not included in the final model due to lack of association with weight gain.

dren of smoking mothers generally had a shorter length of breast feeding compared with those of non-smoking mothers (fig 1). In a Cox regression model, children of heavy smoking mothers were, on average, 2.0 (95\% CI, 1.7, 2.3) times and children of light smoking mothers $1.3(1.2,1.5)$ times more likely to have stopped breast feeding during their first year of life compared with children of non-smoking mothers. Independent variables in the model were gender, birth weight, maternal education, maternal age, family income, and single parenthood.

Linear regression analysis adjusting for breast feeding and potential confounders showed that the mean weight gain was $147 \mathrm{~g}(95 \% \mathrm{CI}, 40$, 255) per year greater in the children of light smokers and $184 \mathrm{~g}(44,324)$ per year greater in the children of heavy smokers compared with children of non-smokers. The adjusted effect of breast feeding on weight gain was $-38 \mathrm{~g}(-50,-27)$ per month of breast feeding. Table 4 shows corresponding crude and adjusted estimates separately for boys and girls. Inclusion of breast feeding in the linear re- gression model reduced the effect of smoking on weight gain. The adjusted effect of breast feeding did not differ essentially from the crude estimates. Covariates indicating socioeconomic status and ETS exposure did not contribute significantly to the models.

\section{Discussion}

Understanding the determinants of growth in early life is important, because there is increasing evidence that growth disturbance at this time predicts later health conditions such as the occurrence of respiratory symptoms, ${ }^{15}$ coronary heart disease, ${ }^{16-18}$ glucose intolerance, ${ }^{19}$ and obesity in childhood and adulthood. ${ }^{2021}$ Our one year cohort study of Oslo children offered an opportunity to assess the role of maternal smoking during pregnancy and the length of breast feeding as determinants of weight gain during the first year of life. Compared with the children lost to follow up or excluded from the analysis, the children included had a somewhat higher socioeconomic status and birth weight. Still, the mean birth weight and weight gain during the first year of life of children included in the analysis was as expected for Norwegian children. ${ }^{11}$ Exclusion of children with low birth weight and difference in willingness to participate related to socioeconomic status could both have affected the maternal smoking rate and length of breast feeding. This shows the necessity to control for confounding when studying the relation between smoking, breast feeding, and weight gain. Exclusion of children with a low birth weight may have decreased the magnitude of differences in birth weight in relation to smoking status. Even so, the birth weight was, consistent with previous knowledge, on average lower in newborns of mothers who smoked than in newborns of mothers that did not smoke during pregnancy.

During the first year of life, the children of smoking mothers gained weight faster and by the age of 1 year both their average body weight and body mass index were similar to those of the children of non-smoking mothers. Our observations are thus consistent with the recent report by Conter. ${ }^{7}$ As a new observation, our results indicate that part of the catch up growth could be explained by the shorter duration of breast feeding in smokers, while the length of breast feeding was inversely related to weight gain. However, the average weight gain was somewhat higher in children of smoking mothers, even after controlling for the duration of breast feeding. The effects on weight gain due to maternal smoking and breast feeding were shown for both genders, even though it seemed to be stronger in girls. The median length of breast feeding in the present study was nine months, which is lengthy in international terms, but consistent with a previous report from Norway. ${ }^{22}$ Our large scale, population based cohort study confirms the observation by Feinstein $e t a l^{10}$ on the relationship between maternal smoking and the duration of breast feeding. Partly because of the lengthy breast 
feeding we were also able to provide a quantitative estimate of the relation.

Socioeconomic factors did not significantly contribute to the catch up growth. This is not surprising. The level of education and family income among participating families were generally high and sufficient for adequate nourishing of children both during the breast feeding period and afterwards.

Our results suggest that the fetal growth deficit caused by maternal smoking during pregnancy is compensated for by faster weight gain during the first year of life, but part of the faster weight gain is related to the shorter length of breast feeding in smoking mothers. This raises two important questions. Does the catch up in weight represent a true recovery from the adverse effects of smoking on fetal growth and is the weight gain related to mother's smoking and shorter breast feeding desirable?

Funding: The Norwegian Research Council

Conflict of interest: none.

The authors would like to acknowledge the staff at maternity wards at Aker and Ullevål Hospital for their support in data collection, Jennifer Harris for her contibution to the manuscript and Leiv Bakketeig for his contribution in the planning of this cohort study.

1 Kramer MS. Determinants of low birth weight: methodological assessment and meta-analysis. Bull World Health Organ 1987;65:663-737.

2 Dougherty CRS, Jones AD. The determinants of birth weight. Am $\mathcal{f}$ Obstet Gynecol 1982;144:190-200.

3 Martinez FD, Wright AL, Taussig LM, GHMA. The effect of paternal smoking on the birthweight of newborns whose of paternal smoking on the birthweight of newborns whose mothers

4 Fox NL, Sexton M, Hebel JR. Prenatal exposure to tobacco: 1. Effect on physical growth at age three. Int $\mathcal{f}$ Epidemio 1990;19:66-71.
5 Butler NR, Goldstein H. Smoking in pregnancy and subsequent child developement. BMf 1973;4:573-5

6 Rantakallio P. A follow-up study to the age of 14 of children whose mothers smoked during pregnancy. Acta Paediatr Scand 1983;72:747-53.

7 Conter V, Cortinovis I, Patrizia R, Riva L. Weight growth in infants born to mothers who smoked during pregnancy. BMF 1995;310:768-71.

8 Dewey KG, Heinig MJ, Nommesen LA, Peerson JM, Lonnerdal B. Growth of breast-fed and formula-fed infants from 0 to 18 months: the Darling study. Pediatrics 1992; 89:1035-41.

9 Duncan B, Schaefer C, Sibley B, Fonseca NM. Reduced growth velocity in exclusively breast-fed infants. $A F C D$ 1984;138:309-313.

10 Feinstein JM, Berkelhamer JE, Gruszka ME, Wong CA, Carey AE. Factors related to early termination of breastfeeding in an urban population. Pediatrics 1986;78:210-5.

11 Knudtzon J, Waaler PE, Solberg LK, Grieg E, Skjærven R, Steen J, Irgens LM. Høyde, vekt og hodeomkrets hos $0-4$ år gamle barn. Tidsskr Nor Logeforen 1988;108:2136-42 (in Norwegian)

12 Garrow JS, Webster J. Quetelet's index $\left(\mathrm{Wt}_{\mathrm{t}} / \mathrm{H}^{2}\right)$ as a measure of fatness. Int $\mathcal{F}$ Obesity 1985;9:147-53.

13 Nafstad P, Kongerud J, Botten G, Urdal P, Silsand T, Stray Pedersen B, Jaakkola JJK. Fetal exposure to tobacco smoke products: A comparison between self-reported maternal smoking and concentrations of cotinine and thiocyanate in cord serum. Acta Obstet Gynecol Scand 1996;75:902-7.

14 SPSS. SPSS for Windows. Release 6.0. Chicago, SPSS Inc, 1993.

15 Chan KN, Elliman A, Bryan R, Silverman M. Respiratory symptoms in children of low birth weight. Arch Dis Child 1989;64:1294-304.

16 Fall CHD, Vijayakumar M, Barker DJ, Osmond C, Duggleby $\mathrm{S}$. Weight in infancy and prevalence of coronary heart disease in adult life. BMF 1995;310:17-9.

17 Osmond C, Barker DJ, Winter PD, Fall CHD, Simmonds SJ. Early growth and death from cardiovascular diseases in women. BMF 1993;307:519-24.

18 Barker DJ, Winter PD, Osmond C, Margetts B, Simmonds SJ. Weight in infancy and death from ichemic heart disease. Lancet 1989;ii:577-80.

19 Hales CN, Barker DJ, Clark PMS, Cox LJ, Fall CHD, Osmond C. Fetal and infant growth and and impaired glucose intolerance at age 64. BMF 1991;303:1019-22.

20 Ravelli GP, Stein ZA, Susser MW. Obesity in young men after famine exposure in utero and early infancy. $N$ Engl after famine exposure in

21 Dietz WH. Critical periods in childhood for developement of obesity. Am f Clin Nutr 1994;59:955-9.

22 Oshaug A, Botten G. Human milk in food supply statistics. Food Policy 1994;19:479-82. 